\title{
DETERIORATION OF ROAD BARRIER PROTECTION ABILITY DUE TO VARIABLE ROAD FRICTION
}

\author{
Stanislawek, S.; Dziewulski, P. \& Kedzierski, P. \\ Military University of Technology, Faculty of Mechanical Engineering, Department of Mechanics and \\ Applied Computer Science, Sylwestra Kaliskiego Street 2, 00-908, Warsaw, Poland \\ E-Mail: sebastian.stanislawek@wat.edu.pl,pawel.dziewulski@wat.edu.pl, \\ kedzierski.piotr@wat.edu.pl
}

\begin{abstract}
The paper presents an analysis of road barrier performance due to variable friction between tires and the ground under different weather conditions. Analyses are based on the TB42 and TB51 test, wherein a vehicle impacts a KTC 033 and KTC 015 steel barrier. A full-scale experiment using a Renault Midlum truck and a SETRA S215L bus was conducted according to the EN 1317 regulation in order to validate a numerical model. A series of numerical tests were conducted in order to investigate the influence of the friction coefficient $\left(\mu_{w r}=0-1.1\right)$ on the normative test results. We proved that in TB 42 test on a very slippery road, the working width $W_{N}$ is equal to $1.6 \mathrm{~m}$, while for a test conducted in good weather conditions (i.e. a dry and clean road) it is only $0.9 \mathrm{~m}$. Thus, it can be stated that the EN 1317 norm may not provide sufficient information about road barrier safety. The behaviour of a barrier cannot be easily anticipated during impact in poor weather conditions, when surface-wheel contact is insufficient.

(Received in March 2019, accepted in August 2019. This paper was with the authors 2 months for 1 revision.)
\end{abstract}

Key Words: Friction, Road Barrier, Crash Test, Numerical Modelling, Finite Element Method

\section{INTRODUCTION}

Road safety is a very important issue in which a very important role is played by road barriers $[1,2]$; these are usually placed wherever there is a danger of vehicle falling from a height or to minimize the risk of vehicle collision with other road users or roadside obstacles. After impact, a barrier should redirect the vehicle away from other traffic within a narrow angle, thus causing it to move along the protector without turning over. Achieving all these goals is difficult if - besides the effectiveness of barrier protection - aesthetic appearance, regional development, environmental effects and most importantly, investment cost is considered [3]. Therefore, the structure of vehicles, in particular suspension, is also very important in order to provide occupant protection in the event of a crash into a barrier. A number of factors define crashworthiness and therefore developing a methodology which can assess barrier safety is a complex issue [4, 5]. European Normative EN1317 [6, 7], US test protocol MASH [8] or Australian/New Zealand Standard AS/NZS 3845.1-2015 [9] are standards which define assessment parameters and test procedures. Moreover, numerous papers have investigated the problem of friction during a crash. It has been proven in [10] that the friction coefficient, especially in winter, may vary significantly, and this may change the sequence of events during an accident. In [11] research on frontal crash severity in different road environments is presented; it was shown by a case study that increasing surface friction causes a significant increase in crash severity for single vehicle crashes. The effect of friction on the rate of crashes in both wet and dry conditions is evaluated in [12]; the authors suggest friction thresholds for different road classes, which should result in a reduction in the crash rate. Some papers deal with the influence of horizontal curves on the occurrence of crashes [13, 14]. The authors agree that crash statistics show that crashes are most likely to occur at bends in the road and that these collisions usually involve at least some level of injury. Lateral friction measurement or even high-friction surface treatment is suggested. In [15] a low-profile 
portable concrete barrier system is presented for use in roadside work zone environments. The authors developed an advanced model of friction and claim that this is critical for redirecting vehicles in an impact simulation. Some authors have also considered the problem of friction between barrier and vehicle [16]. This problem is crucial for situations when tires interact with the structure of a safety system, though, it is less important when a steel barrier is used. In such cases, the vehicle body impacts the barrier guardrail when the friction coefficient is relatively small and cannot vary much depending on the weather. Summarising, many researchers agree that the adhesion of vehicles' wheels to the road surface has a direct impact not only on the barrier impact phenomenon but also on the further trajectory of vehicles. A vehicle usually skids after a crash, which causes sliding friction that acts with a relatively high force in opposition to the direction of movement. Unfortunately, a general solution for the improvement of safety has not been suggested. The most common EN 1317 standard describes in detail the criteria of impact tests and the requirements of systems that limit the road area; however, the deterioration of the protection ability of road barriers due to varying friction in different weather conditions has not been considered. Therefore, the purpose of the paper is to verify the influence of different friction coefficients based on an impact between a truck and a side barrier according to the EN 1317 standard.

\section{PROBLEM SOLUTION}

Safety barriers in Europe have to fulfil the EN 1317 standard in terms of their functional characteristics, such as a restraint level, working width and collision intensity level. The collision intensity level reflects the impact of the collision on the occupants of the vehicle; however, it is not required for trucks. The working width $\left(W_{N}\right)$ of a barrier is the distance between the side of the guardrail facing the traffic and the maximum lateral position of any major part of the system during vehicle impact. Dynamic deflection $\left(D_{m}\right)$ is the maximum lateral displacement of the traffic face of the restraint system during the impact. Based on these parameters, a restraint level ( $\mathrm{T}$ - temporary, $\mathrm{N}$ - normal, $\mathrm{H}$ - high, $\mathrm{H} 4$ - very high) may be determined, using appropriate crash test results. Another parameter, VCDI, is the deformation index of the vehicle compartment; it describes the location and extent of damage to the vehicle cab. It depends on the particular design of a vehicle and may differ from test to test for the same barrier type. Obviously, other parameters are also measured during onsite tests, which help to assess barrier functionality. In this paper, working width and dynamic deflection are considered, as it is believed that they universally represent safety during a crash.

EN 1317 takes into account neither friction coefficient nor road surface. However, in the literature [10,17-19] it has been proven that in different weather conditions this coefficient may vary from 0.05-1.2. Therefore, though a barrier may undergo a normative test successfully, it may not provide sufficient protection for road users.

Two types of high-containment barrier systems were tested: H2 level KTC 033 [20] and H1 level KTC 015 [21], impacted with a truck and a bus respectively. A series of tests was conducted in order to investigate the problem. Computer simulation was chosen as the most effective way of solving the problem. Numerical calculations were performed using the LSDYNA [22] non-linear finite element code, a commonly-used tool for solving problems associated with crashes and impacts [23-25]. An explicit integration scheme was used to solve the equation of motion.

\subsection{Numerical model}

Two numerical models were built to simulate the TB42 and TB51 normative tests. The first model represents a KTC 03364 m-long commercially-available barrier, comprising ninety 
thousand shell elements with five integration points per thickness. The distance between posts is $2 \mathrm{~m}$ and the height of the barrier is $0.78 \mathrm{~m}$. Both posts and guardrail are made of steel, whose yield stress is $340 \mathrm{MPa}$ and plastic strain to failure 0.6. Key elements of this model are the screw connections as they determine the behaviour of the barrier. Therefore, proper description of their stiffness and destruction process is crucial. The screw connections are relatively small in comparison to other components of the model. Precise modelling using shell and brick elements would increase the computational time drastically. Thus, a simplified method was used wherein the whole connection was modelled utilizing a beam element with precisely-defined characteristics that were determined for elements damaged during a crash. The tensile strength of connection between posts and guardrail was $31 \mathrm{kN}$ and guardrail components was $54 \mathrm{kN}$. The truck model was compatible with the EN 1317 standard [7]. The model included friction between the vehicle, barrier, wheels and the ground. The vehicle barrier kinematic friction coefficient was $\mu_{v b}=0.05$ and the wheel - road coefficient was $\mu_{w r}$, with a range of $0-1.1$. The total mass of the truck was significant (10 tons), thus the model included gravity. The model before impact is presented in Fig. 1.

The second model represents the KTC 015 barrier and a 12.5 ton bus. The numerical model description is presented in [26].

a)

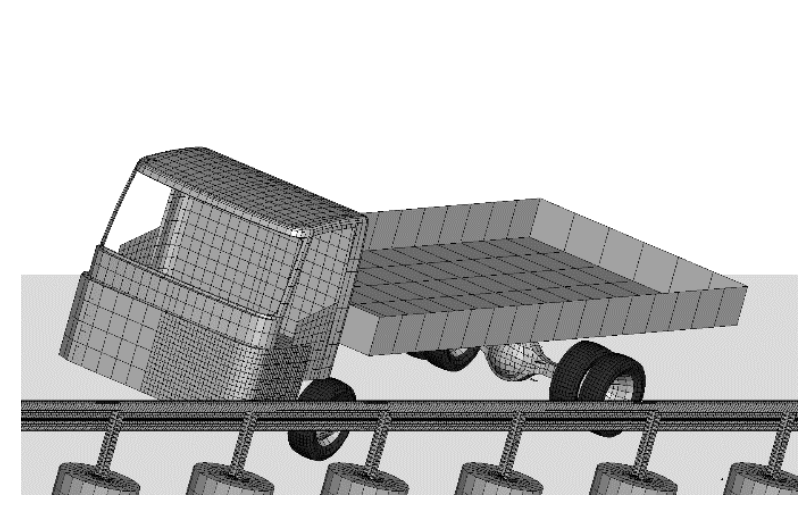

b)

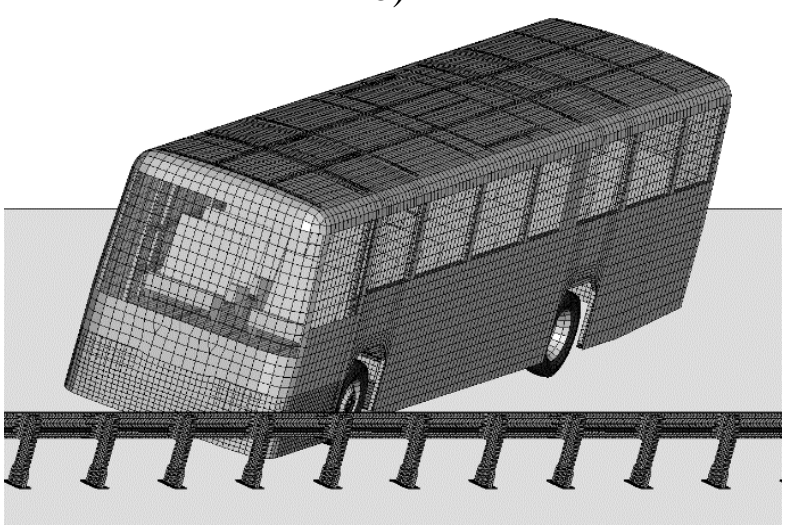

Figure 1: Numerical models: a) KTC 033 side barrier and truck, b) KTC 015 side barrier and bus.

\subsection{Experimental procedure}

The TB42 experimental test was conducted on site with a Renault Midlum vehicle. The mass of the truck was not high enough according to [4]; therefore, additional ballast (4.36 tons) was fixed on the platform floor. KTC 033 barrier posts were rammed into loose ground to a depth of $0.9 \mathrm{~m}$. The vehicle hit the barrier between post 7 and 8 at a speed of $71 \mathrm{~km} / \mathrm{h}$ and an angle of $14.40^{\circ}$; it was in contact with the barrier for a distance of $22.8 \mathrm{~m}$. Posts 9-12 and 14-17 were detached from the beam and bent to the ground. Post 13 was totally detached and separated. The left and right front wheels and the dumper were damaged. The left front corner of the vehicle was deformed. The tested barrier produced a positive result. Three high-speed cameras were used to record the test. Two cameras were placed along the barrier at its leading edge and the end. The third was situated over the test point.

A full-scale experiment was conducted on-site using a SETRA S215L bus. After reaching a speed of $74 \mathrm{~km} / \mathrm{h}$, the vehicle hit the barrier at an angle of $19.40^{\circ}$ between Post No. 16 and No. 17 and was in contact with it for a length of $35.81 \mathrm{~m}$. The tested barrier achieved a positive result according to the TB51 collision test. Information on normalization procedure for $W_{N}$ and $D_{N}$ and the results of the TB51 test are reported in [26]. 


\section{RESULTS AND DISCUSSION}

\subsection{Validation}

The initial conditions of the experiments were represented in numerical tests. During the truck crash the tires interacted with two types of surfaces: concrete and - where the barrier was mounted - gravel. According to the literature, each surface has a different friction coefficient, depending on a variety of factors (especially the speed of the vehicle). The friction coefficients for dry concrete and gravel are $0.75-0.9$ and $0.4-0.7$, respectively [18]. Due to this, in numerical simulations the friction coefficient which best represents the described experiments was not considered to be a specific number, but to be in the range 0.6-0.8. Deformations captured at selected moments during the crash test are presented in Fig. 2. The simulation results are presented for the same moments.
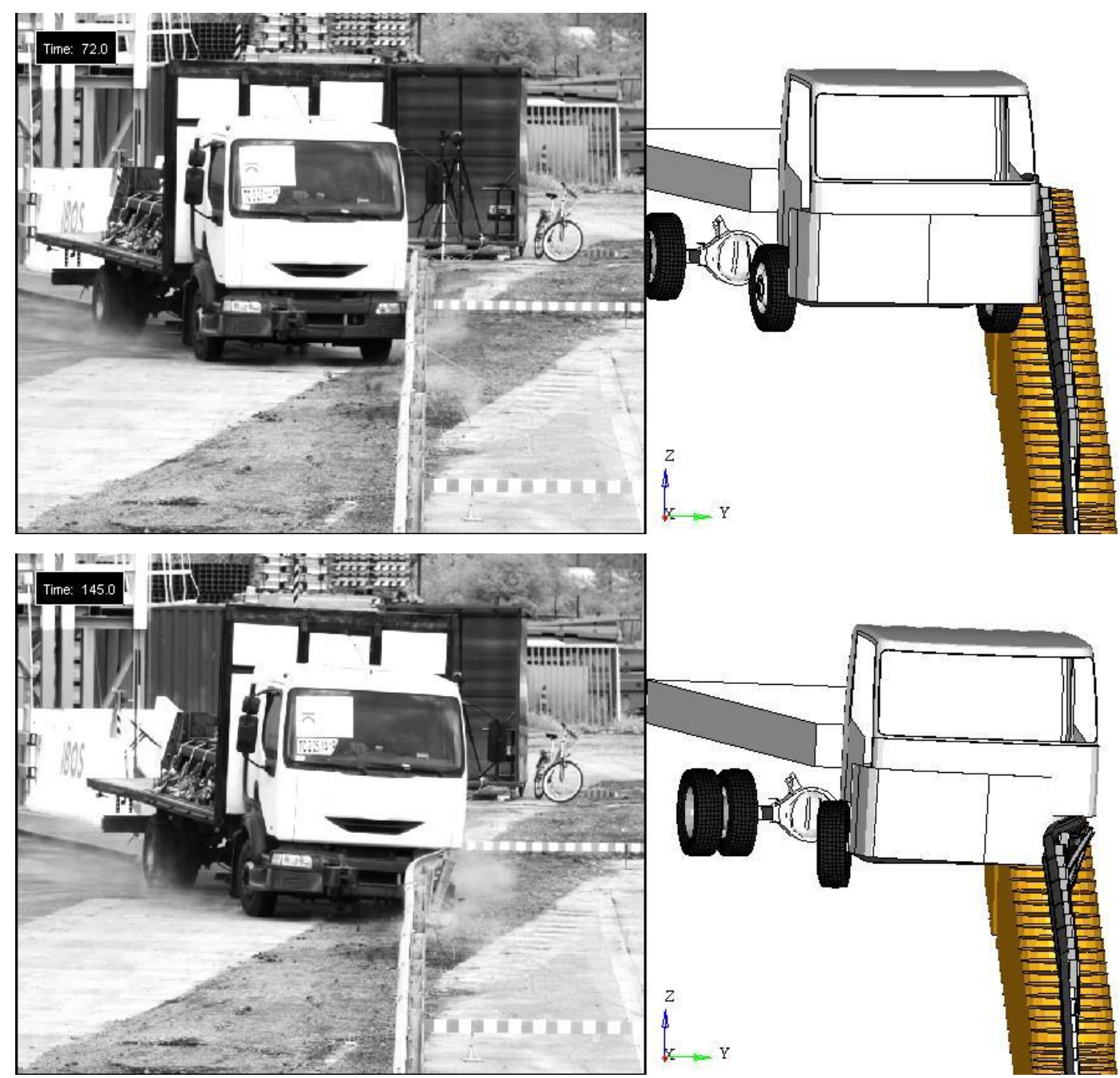

Figure 2: Deformation of truck and barrier in the experimental test and numerical simulation.

The behaviour of the truck during the TB 42 experimental test was similar to that observed in the numerical simulation. In both the experimental test and its numerical representation, the barrier's guardrail was significantly deformed and detached from some of the posts. Table I presents the functional parameters: normalized dynamic deflection $\left(D_{m}\right)$, which is the maximum lateral displacement of the traffic-facing side of the restraint system during impact; normalized working width $\left(W_{N}\right)$, which is the maximum transverse distance measured during the test. 
Validation of the numerical model, in which a bus impacts a KTC 015 side barrier according to TB51 requirements, is presented in [26].

Table I: Functional parameters of the barrier in the numerical simulation and the experimental test.

\begin{tabular}{|c|c|c|c|}
\hline \multirow{2}{*}{ Parameter } & \multirow{2}{*}{ Experiment } & \multicolumn{2}{|c|}{ Numerical simulation } \\
\cline { 3 - 4 } & & $\boldsymbol{\mu}_{w r}=\mathbf{0 . 6}$ & $\boldsymbol{\mu}_{w r}=\mathbf{0 . 8}$ \\
\hline$W_{N}$ (working width) & $1 \mathrm{~m}$ & $1.12 \mathrm{~m}$ & $1.05 \mathrm{~m}$ \\
\hline$D_{m}$ (dynamic deflection) & $0.9 \mathrm{~m}$ & $1 \mathrm{~m}$ & $0.93 \mathrm{~m}$ \\
\hline
\end{tabular}

\subsection{Friction coefficient sensitivity}

A detailed observation of the TB42 crash test phenomenon raises the question of the effect of friction on the barrier's protection ability. From the video recordings of the experiment, it can be observed that the gravel on which the truck is moving scatters as the wheels slip toward the barrier. It can be assumed that surfaces that generate lower friction forces may change the behaviour of a vehicle with high inertia. Thus, the same road barrier may not provide sufficient protection in different weather conditions. In fact, vehicles rarely move on concrete roads covered with gravel; however, as is often mentioned in the literature, the properties of an asphalt surface may change drastically, especially in winter.

In order to investigate the influence of the friction coefficient on the crash phenomenon, a set of friction coefficients were used in the simulations. A series of tests were conducted for coefficients of friction $\mu_{w r}=0,0.2,0.4,0.6,0.8,1$, and 1.1.

Simulation of the TB42 test showed serious damage to the barrier, especially for small values of $\mu_{w r}$. The guardrail was detached from the posts due to damage to the absorbers during the crash of the front part of the vehicle and the subsequent impact in the same area by the rear of the truck, which caused further damage. Although the guardrail was not fractured, it is flexible and therefore could not stop the intrusion of the vehicle. The influence of friction on vehicle behaviour is depicted in Fig. 3. On a very slippery road with ice, for example, (Fig. 3 a) both left wheels went through the barrier, which does not provide sufficient protection according to EN 1317; therefore, the vehicle would not pass the normative test successfully. For relatively poor surfaces like earth roads, gravel or wet asphalt (Fig. $3 \mathrm{~b}$ ), the barrier stops the truck satisfactorily. For surfaces that provide very good contact with tires, such as dry and clean concrete, the barrier also passes the test successfully (Fig. $3 \mathrm{~b}$ ) and the vehicle returns to its original traffic lane slightly more quickly.

During the TB51 test, some absorbers were also quickly damaged; however, as the vehicle is relatively long, the rear part of the bus impacted an undeformed part of the barrier system. The bus did not go through the barrier in either of the simulations.

The simulation results were evaluated according to the specific requirements of EN 1317. A graph (Fig. 4) presenting $W_{M}$ and $D_{m}$ shows that the friction force generated due to the interaction between tires and the road surface may be a decisive factor in crash test results. The TB51 simulation results are quite similar, regardless of the friction level. However, in TB42 simulations where a low friction coefficient is defined, increased values of working width and dynamic deflection are registered. In such events, the small force opposing movement towards the barrier cannot successfully stop the vehicle from intrusion into the guardrail, thus causing significant damage. A very small influence can be observed for friction coefficients in the range 0.9-1.1, as friction is high enough to stop the tires from slipping and vehicle movement is possible mainly due to the turning of its wheels. 
a)

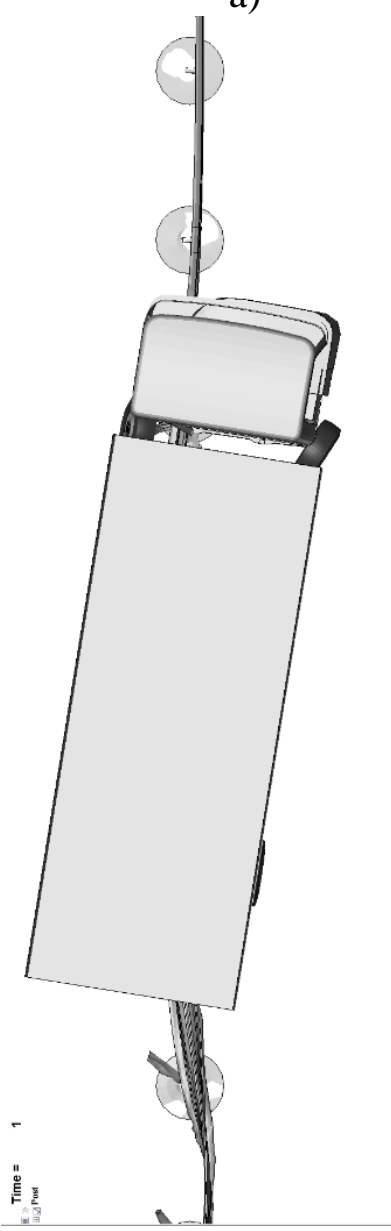

b)

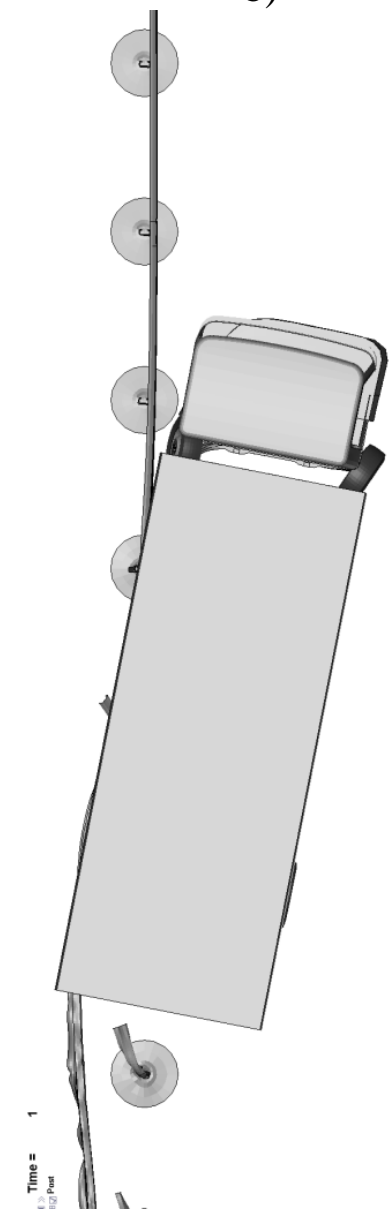

c)

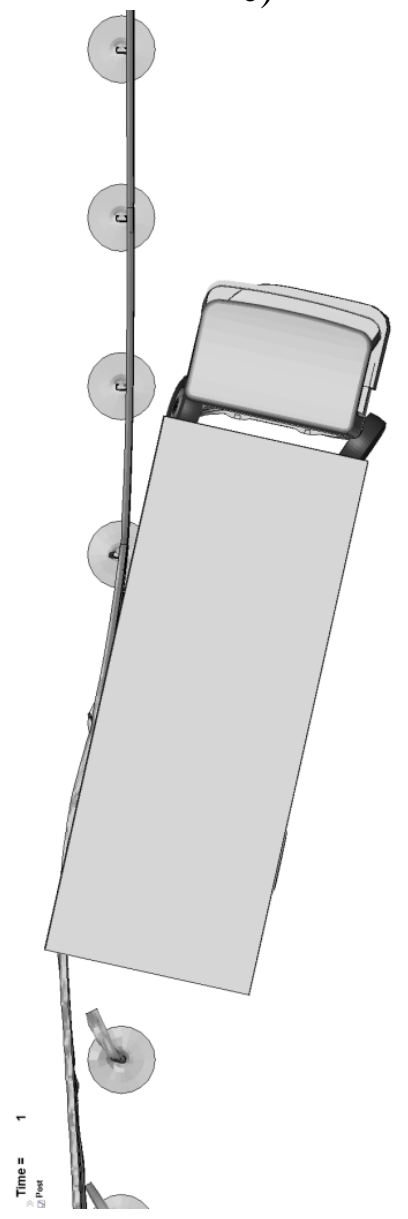

Figure 3: Position of the vehicle $1 \mathrm{~s}$ after the impact when different friction coefficients were used: a) $\mu_{w r}=0$, b) $\mu_{w r}=0.6$, c) $\mu_{w r}=1$.

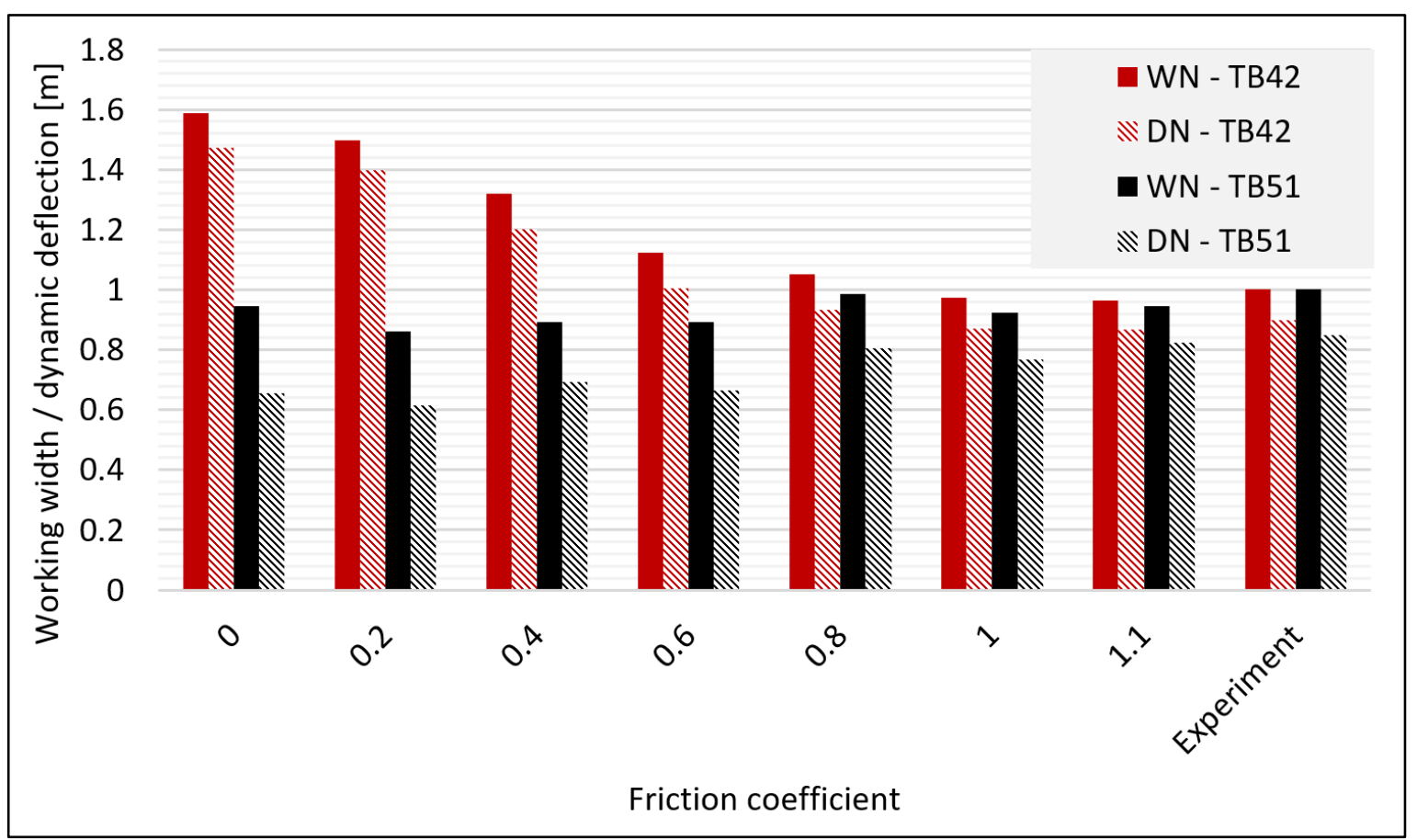

Figure 4: Numerical test results: working width $\left(W_{N}\right)$ and dynamic deflection $\left(D_{N}\right)$ for friction coefficient $0-1.1$. 
To prove this hypothesis, the trajectory of a point located on the left rear wheel was registered; the results shown in Fig. 5 a confirm this assumption. For friction coefficients 11.1, the trajectory of the rear wheel is almost the same. The bus trajectory presented in Fig. $5 \mathrm{~b}$ also shows the influence of friction, but the difference is not significant. The KTC 015 system is a high containment system level that is able to withstand a bigger load. This type of barrier is usually mounted on bridges and its posts are firmly mounted in concrete foundations. The authors assume that this is why vehicle skidding did not result in serious intrusion into the restraint system.

a)

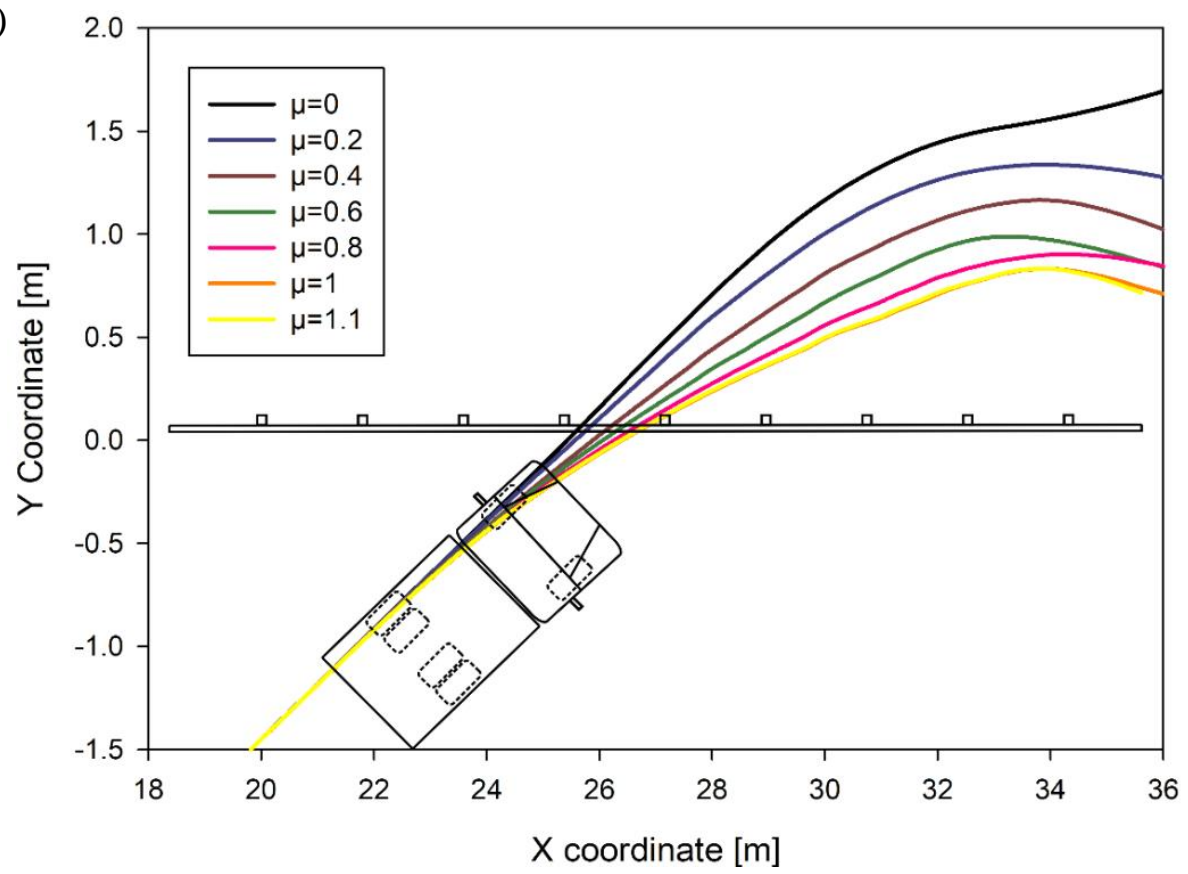

b)

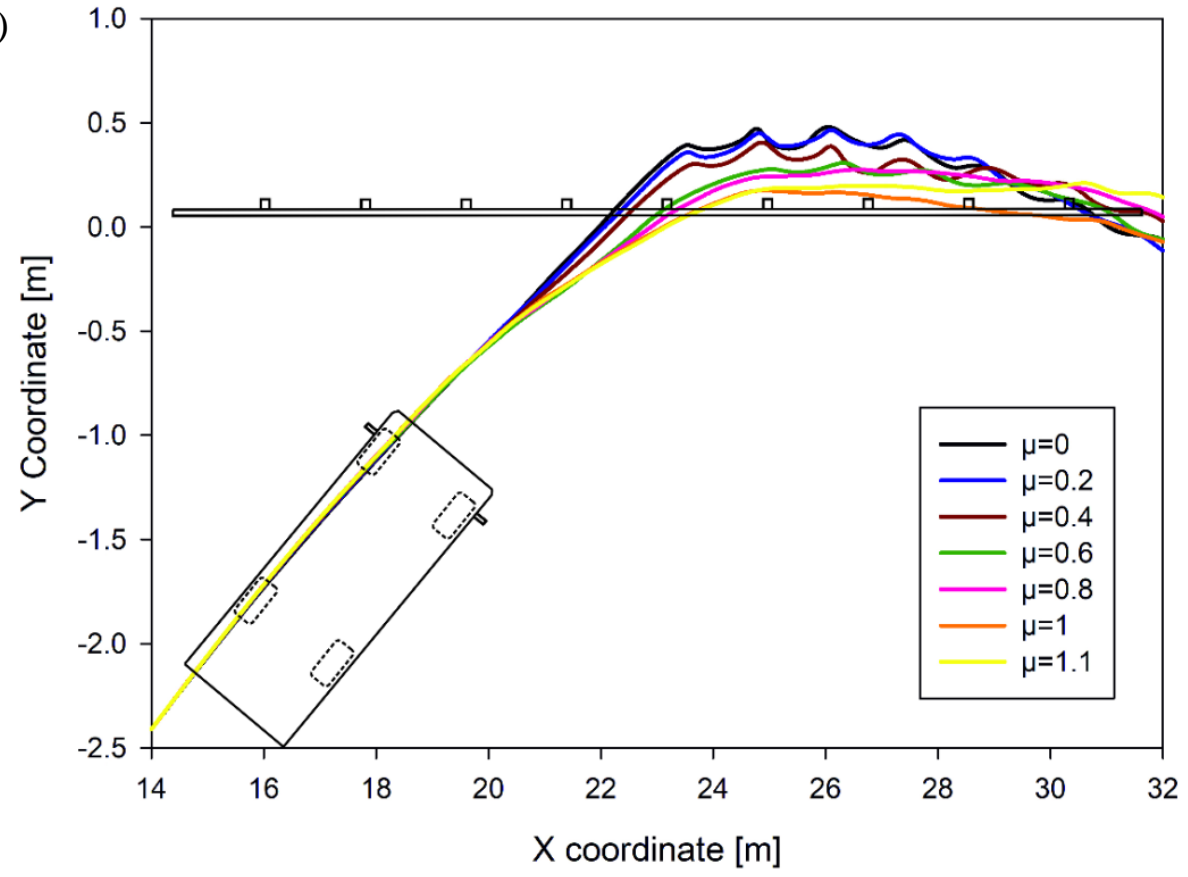

Figure 5: Trajectory of a point located on the vehicle's rear left tire with symbolic representation of the barrier and the vehicle: a) TB42 test, b) TB51 test.

Summarizing the crash phenomenon is a complicated process in which, one the one hand, a small ground-vehicle friction stops the intrusion of the vehicle because the reaction forces of 
the barrier may more easily move its body. On the other hand, such little friction causes that inertia, especially of the rear part of vehicle, making it hit with higher energy. The influence of each effect depends on the design of particular vehicle and barrier. In the analysed tests, the rigid truck impact test (TB42) showed that low friction causes much more damage to the barrier structure. However, in the case of the TB51 test, the bus is redirected a little faster and the dynamic deflection slightly increased for high friction. Even so, all the results for the TB51 test are relatively similar and therefore it can be said that in this case friction influence on the barrier protection ability may be disregarded. Consequently, it is clear that the effect of high energy impact may be dominant in certain conditions and that is why variable road conditions are an important issue.

\section{CONCLUSION}

The paper presents an analysis of road barrier performance during crashes in different weather conditions that cause varying degrees of friction between the wheels and the ground. Analyses are based on the TB 42 and TB51 tests, in which a vehicle impacts a KTC 033 or KTC 015 steel barrier at a velocity of $70 \mathrm{~km} / \mathrm{h}$. A series of numerical tests were conducted in order to investigate the influence of the friction coefficient $\left(\mu_{w r}=0-1.1\right)$ on the normative test results.

The results obtained prove that the trajectory of a vehicle is affected by friction during a crash. On a slippery road, the rear part of the vehicle skids and impacts the barrier with high velocity. In the case of a truck impact, this phenomenon leads to the TB42 crash test being failed. The working width in the test, $W_{N}$, for a very slippery road is equal to $1.6 \mathrm{~m}$, while for a test conducted in good weather conditions on a good quality road it is only $0.9 \mathrm{~m}$. Moreover, for much less realistic scenarios in which the coefficient is above $\mu_{w r}>0.9$, the vehicle behaviour does not change; this means that the truck stops sliding and its movement is caused mainly by the rotation of its wheels. These assumptions are proved by observation of the trajectory of the rear wheels, which remains unchanged in the case of $\mu_{w r}=0.9-1.1$ for these simulation tests. The TB51 crash analysis also showed similar effects, but it did not result in increased vehicle intrusion.

To sum up, it can be stated that the EN 1317 norm may not provide sufficient information about road barrier safety. Behaviour of a barrier during impact in poor weather conditions, when the road-wheel friction is low, cannot be easily anticipated. Unfortunately, performing an experimental crash test on a slippery surface is technically difficult and would generate additional costs. Therefore, numerical simulations are an efficient way to test barriers.

\section{REFERENCES}

[1] Elvik, R. (1995). The safety value of guardrails and crash cushions: A meta-analysis of evidence from evaluation studies, Accident Analysis \& Prevention, Vol. 27, No. 4, 523-549, doi:10.1016/0001-4575(95)00003-I

[2] Zain, M. F. B. M.; Mohammed, H. J. (2015). Concrete road barriers subjected to impact loads: An overview, Latin American Journal of Solids and Structures, Vol. 12, No. 10, 1824-1858, doi: $\underline{10.1590 / 1679-78251783}$

[3] Karim, H. (2011). Road Design for Future Maintenance - Life-cycle Cost Analyses for Road Barriers, Doctoral Thesis, Department of Civil and Architectural Engineering, Division of Highway and Railway Engineering, Royal Institute of Technology (KTH), Stockholm

[4] Abraham, N.; Ghosh, B.; Simms, C.; Thomson, R.; Amato, G. (2016). Assessment of the impact speed and angle conditions for the EN1317 barrier tests, International Journal of Crashworthiness, Vol. 21, No. 3, 211-221, doi:10.1080/13588265.2016.1164444

[5] Wu, W.; Thomson, R. (2004). Compatibility between passenger vehicles and road barriers during oblique collisions, International Journal of Crashworthiness, Vol. 9, No. 3, 245-253, doi: $\underline{10.1533 / i j c r .2004 .0281}$ 
[6] EN 1317-1:2010. Road restraint systems - Part 1: Terminology and general criteria for test methods, European Standard

[7] EN 1317-2:2010. Road restraint systems - Part 2: Performance classes, impact tests acceptance criteria and test methods for safety barriers including vehicle parapets, European Standard

[8] Manual for Assessing Safety Hardware (2009), American Association of State Highway and Transportation Officials (AASHTO), Washington, D.C.

[9] CE-033: AS/NZS-3845.1:2015. Road safety barrier systems and devices - Road safety barrier systems, Standards Australia/Standards New Zealand, Sidney/Wellington

[10] Fujimoto, A.; Fukuhara, T.; Watanabe, H.; Takeshi, T.; Miyazaki, N. (2004). Friction coefficients on winter road surfaces using Multi-Axial Sensing system vehicle, Proceedings of the Fifth International Conference on Snow Engineering, 15-21

[11] Ydenius, A. (2009). Frontal crash severity in different road environments measured in real-world crashes, International Journal of Crashworthiness, Vol. 14, No. 6, 525-532, doi:10.1080/ 13588260802671407

[12] Najafi, S.; Flintsch, G. W.; Medina, A. (2017). Linking roadway crashes and tire-pavement friction: a case study, International Journal of Pavement Engineering, Vol. 18, No. 2, 119-127, doi: 10.1080/10298436.2015.1039005

[13] Buddhavarapu, P.; Banerjee, A.; Prozzi, J. A. (2013). Influence of pavement condition on horizontal curve safety, Accident Analysis \& Prevention, Vol. 52, 9-18, doi:10.1016/ j.aap.2012.12.010

[14] Geedipally, S. R.; Pratt, M. P.; Lord, D. (2019). Effects of geometry and pavement friction on horizontal curve crash frequency, Journal of Transportation Safety \& Security, Vol. 11, No. 2, 167-188, doi:10.1080/19439962.2017.1365317

[15] Consolazio, G. R.; Chung, J. H.; Gurley, K. R. (2003). Impact simulation and full scale crash testing of a low profile concrete work zone barrier, Computers \& Structures, Vol. 81, No. 13, 1359-1374, doi:10.1016/S0045-7949(03)00058-0

[16] Trajkovski, J.; Ambrož, M.; Kunc, R. (2018). The importance of friction coefficient between vehicle tyres and concrete safety barrier to vehicle rollover - FE analysis study, Strojniski vestnik - Journal of Mechanical Engineering, Vol. 64, No. 12, 753-762, doi:10.5545/sv-jme.2018.5290

[17] Singh, K. B.; Taheri, S. (2015). Estimation of tire-road friction coefficient and its application in chassis control systems, Systems Science \& Control Engineering, Vol. 3, No. 1, 39-61, doi: $10.1080 / 21642583.2014 .985804$

[18] Wong, J. Y. (2001). Theory of Ground Vehicles, $3^{\text {rd }}$ ed., John Wiley \& Sons, New York

[19] Persson, B. N. J.; Tartaglino, U.; Albohr, O.; Tosatti, E. (2005). Rubber friction on wet and dry road surfaces: The sealing effect, Physical Review B, Vol. 71, No. 3, Paper 035428, 8 pages, doi:10.1103/PhysRevB.71.035428

[20] KTC SERVICE. Single safety barrier KTC 033, from https://ktcservice.pl/produkty/ktc-033/, accesed on 01-03-2019

[21] KTC SERVICE. Single bridge safety barrier KTC 015, from https://ktcservice.pl/produkty/ktc015/, accesed on 01-03-2019

[22] Hallquist, J. O. (2006). LS-DYNA ${ }^{\circledR}$ Theory Manual, Livermore Software Technology Corporation, Livermore

[23] Mantaras, D. A.; Luque, P. (2015). Assessing motorcyclist protection systems using finite element simulations, International Journal of Simulation Modelling, Vol. 14, No. 1, 110-120, doi:10.2507/IJSIMM14(1)10.294

[24] Stanislawek, S.; Morka, A.; Niezgoda, T. (2011). A composite consisting of a set of hexagonal ceramic bars - The numerical study of the ballistic resistance, Key Engineering Materials, Vols. 471-472, 1142-1146, doi:10.4028/www.scientific.net/KEM.471-472.1142

[25] Vesenjak, M., Ren, Z. (2003). Dynamic analysis of a road-restraint system's deformation resulting from a vehicle impact, Strojniski vestnik - Journal of Mechanical Engineering, Vol. 49, No. $12,586-592$

[26] Dziewulski, P.; Stanisławek, S. (2019). The impact of forming processes on road barrier strength, AIP Conference Proceedings, Vol. 2078, No. 1, Paper 020003, 7 pages, doi:10.1063/1.5092006 